\title{
Contralateral subdural haematoma as remote secondary lesion in head injury
}

\author{
Saurabh Jain \\ Department of Neurosurgery, GBH American Hospital, Udaipur, Rajasthan, INDIA
}

\begin{abstract}
Contalateral extra axial hemorrhage after cranial surgery is uncommon but known phenomenon. Most of these hemorrhage are epidural (4) or intraparenchymal (6). The subdural being the rarest with only nine cases reported till date.

We are presenting a case of development of contralateral subdural hematoma after decompressive craniectomy for traumatic SDH.
\end{abstract}

\section{Introduction}

Traumatic brain injury is a modern epidemic involving the most productive age group. The burden of traumatic brain injury (TBI), is significant in any society. The early intervention is required for better outcome. The TBI is usually limited to any one particular region when it comes to hematoma.

Early evacuation of hematoma (within four hours) usually associated with favorable outcome.

Remote secondary lesions are known as lesions which occur at site different than the primary site and spaced well in time.

The remote secondary lesions are usually in the form of extradural hematoma or parenchymal contusions. $(4,6)$

Here we are discussing the subdural hematoma as remote secondary lesions.

\section{Case}

A 40 year old male brought by paramedics with road traffic accident with head injury. On examination he was unconscious, intubated, pulse $74 / \mathrm{min}$, blood pressure $130 / 80 \mathrm{~mm}$ of hg with Glasgow coma scale of E1VTM4. Pupils were reacting $3 \mathrm{~mm}$ bilaterally.

On imaging the NCCT (Figure 1) is suggestive of left frontotemporoparietal subdural hematoma with mass effect and midline shift with diffuse cerebral edema. There are evidence of bilateral subarachnoid hemorrhage.

In view of large Subdural hematoma with mass effect, patient was subjected to immediate decompressive craniectomy with evacuation of subdural hematoma with lax duroplasty.

Patient kept ventilated in immediate postoperative period. 
After about five hours patient developed bradycardia with hypertension. $\mathrm{He}$ was imaged by NCCT Scan (Figure 2) which suggest craniotomy defect on left side with remote secondary lesion in the form of subdural hematoma in right side. There is midline shift of about $8 \mathrm{~mm}$ towards left side in contrast to $4 \mathrm{~mm}$ midline shift towards right in pre-operative scan.

Patient was immediately subjected to opposite side craniectomy with $\mathrm{SDH}$ evacuation and lax duroplasty. Patient kept ventilated in post-operative period but the patient keep on deteriorating and succumbed after about three hours of second surgery.

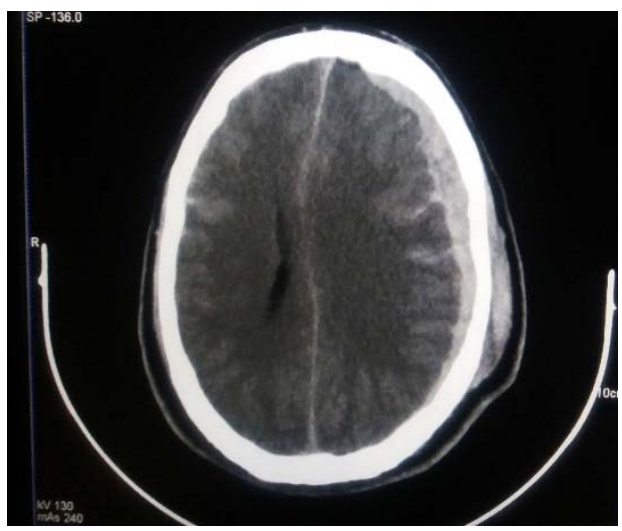

Figure 1

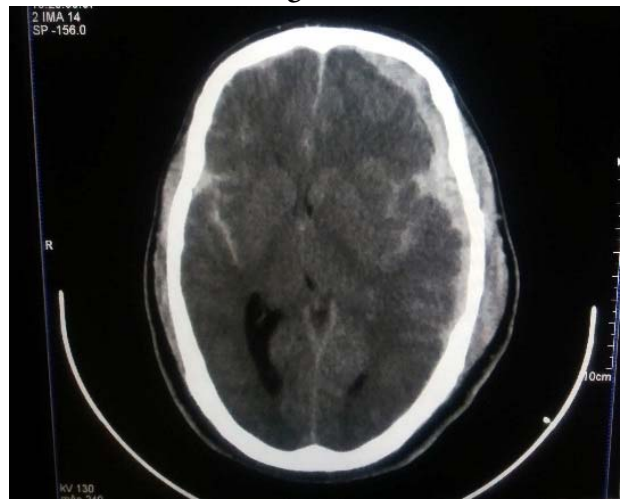

Figure 2

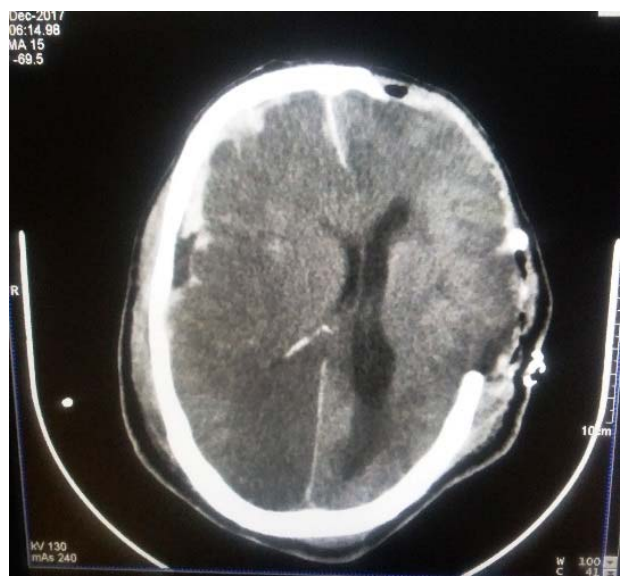

Figure 3

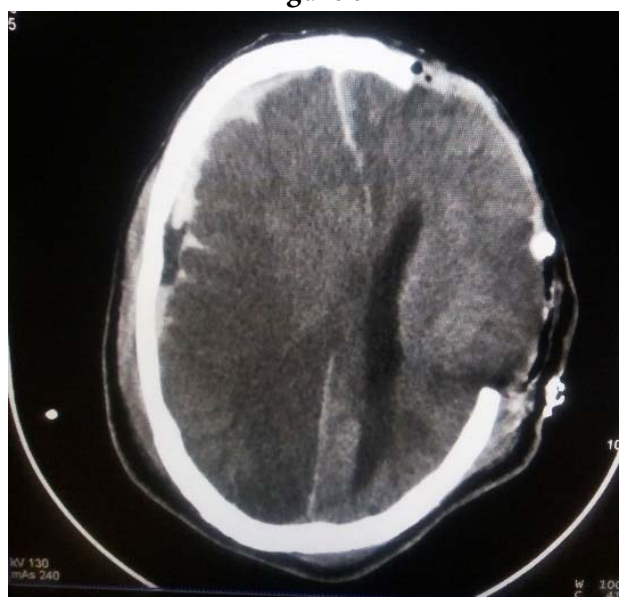

Figure 4

\section{Discussion}

Remote secondary lesions are defined as lesions which are developed at a later stage of previous imaging at a site other than previous lesion. The most common lesion is being the parenchymal hemorrhage followed by extra dural hematoma subdural hematoma is the rarest.

There are only nine case report are there in world English literature of SDH being the remote secondary lesion, $(1-3,5)$ we are presenting the tenth. 
The exact cause of remote secondary lesion is not known but it is assumed that the remote secondary lesions are nothing but lesions under development of primary impact which left unrecognized due to its very small size in early imaging that increases later on.

Another hypothesis that is more relevant in post-operative cases is that decompression of one side causes the opening of small bleeders that were stopped due to compression of edematous brain.

Though the second hypothesis is more relevant in secondary EDH wile the first is for SDH and Parenchymal bleed.

Irrespective of theory of development of remote secondary lesion the lesion should be suspected in every patient and tackled earliest once detected.

\section{Correspondence}

Dr. Saurabh Jain

drsaurabh_jain@rediffmail.com

\section{References}

1. Ban M, Agawa M, Fukami T: Delayed evolution of posttraumatic contralateral extracerebral hematoma after evacuation of initial hematoma. Neurol Med Chir (Tokyo) 31:927-930, 1991

2. Fridley J, Thomas J, Kitagawa R, Chern J, Omeis I: Immediate development of a contralateral acute subdural hematoma following acute subdural hematoma evacuation. J Clin Neurosci 18:422-423, 2011

3. Panourias IG, Skandalakis PN: Contralateral acute epidural haematoma following evacuation of a chronic subdural haematoma with burr-hole craniostomy and continuous closed system drainage: A rare complication. Clin Neurol Neurosurg 108:396-399, 2006

4. Matsuno A, Katayama H, Wada H, Morikawa K, Tanaka K, Tanaka H, Murakami M, Fuke N, Nagashima T: Significance of consecutive bilateral surgeries for patients with acute subdural hematoma who develop contralateral acute epi- or subdural hematoma. Surg Neurol 60:23-30, 2003

5. Panourias IG, Skandalakis PN: Contralateral acute epidural haematoma following evacuation of a chronic subdural haematoma with burr-hole craniostomy and continuous closed system drainage: A rare complication. Clin Neurol Neurosurg 108:396-399, 2006

6. Tomycz ND, Germanwala AV, Walter KA: Contralateral acute subdural hematoma after surgical evacuation of acute subdural hematoma. J Trauma 68:E11-12, 2010 6. Yonezawa K, Kim S, Tanaka M: Acute epidural hematoma following evacuation of chronic subdural hematoma with continuous closed system drainage. Neurol Surg (Tokyo) 20:1013-1016, 1992 